Portland State University

PDXScholar

$5-5-1995$

\title{
A Study of the Duration of Words Surrounding a Moment of Stuttering
}

Jennifer Dawn Peterson

Portland State University

Follow this and additional works at: https://pdxscholar.library.pdx.edu/open_access_etds

Part of the Speech and Rhetorical Studies Commons

Let us know how access to this document benefits you.

\section{Recommended Citation}

Peterson, Jennifer Dawn, "A Study of the Duration of Words Surrounding a Moment of Stuttering" (1995). Dissertations and Theses. Paper 4959.

https://doi.org/10.15760/etd.6835

This Thesis is brought to you for free and open access. It has been accepted for inclusion in Dissertations and Theses by an authorized administrator of PDXScholar. Please contact us if we can make this document more accessible: pdxscholar@pdx.edu. 
The abstract and thesis of Jennifer Dawn Peterson for the Master of Science in Speech Communication: Speech and Hearing Science were presented May 5, 1995, and accepted by the thesis committee and the gepartment.

COMMITTEE APPROVALS :
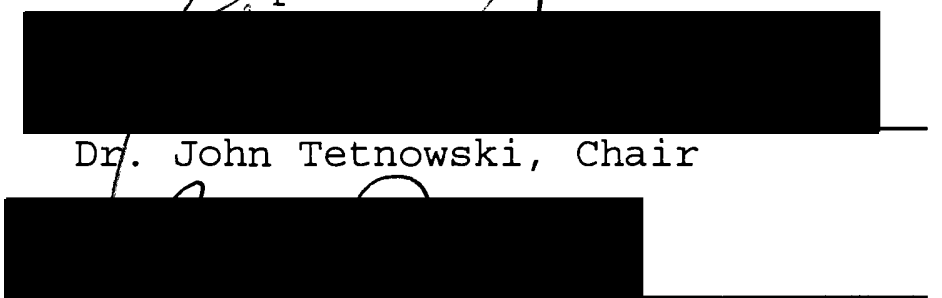

Dr. Rhea Paul
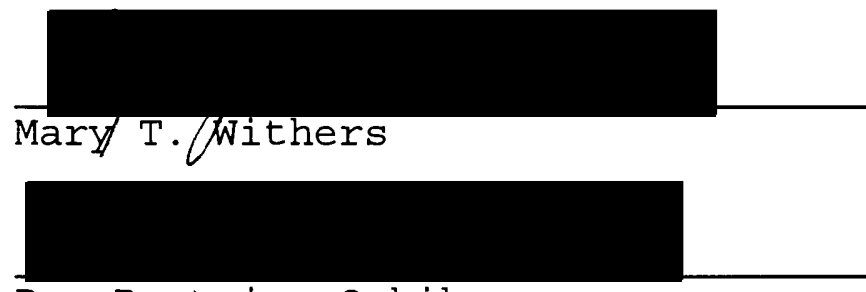

Dr. Beatrice Oshika

Representative of the Office of Graduate studies

DEPARTMENT APPROVAL:

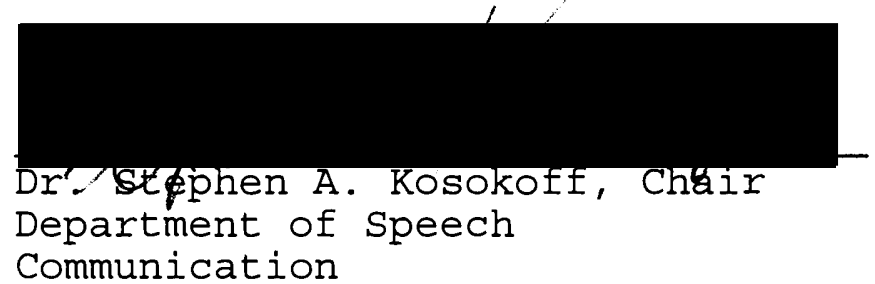

ACCEPTED FOR PORTLAND STATE UNIVERSITY BY THE LIBRARY

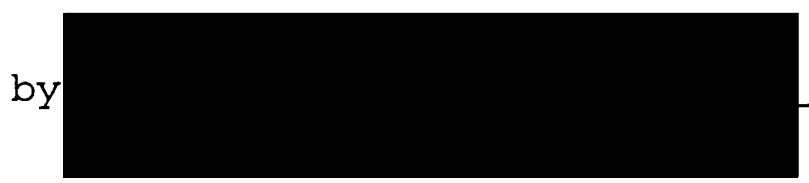

on

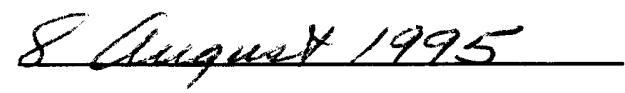




\section{ABSTRACT}

An abstract of the thesis of Jennifer Dawn Peterson for the Master of Science in Speech Communication: Speech and Hearing Science presented on May 5, 1995.

Title: A Study of the Duration of Words Surrounding a Moment of stuttering.

Until this point, not much research has examined the difference in temporal characteristics for untreated stutterers in words surrounding a moment of stuttering. It is important to determine whether or not stutterers who have not been in treatment alter the duration of their speech when they stutter versus when they are fluent to determine what aids in the increase of fluency.

The purpose of the present study was to examine the duration of the word prior to and following a stuttered word and the duration of the corresponding word in a nonstuttered episode. The following questions were to be addressed:

1) Is there a significant durational difference between a word preceding a stuttered word and the duration of the same word in a corresponding nonstuttered sentence?

2) Is there a significant difference between a word following a stuttered word and the duration of the same word in a corresponding nonstuttered sentence? 
Three subjects age 16 and older who had not received treatment for at least 4 years were selected. Subjects were recorded reading a list of 83 sentences selected from Fairbanks (1940) twice. Sentences containing a word that was stuttered in one reading and not in the other were used for analysis. The duration of the following word pairs in milliseconds was computed via the CSRE 4.2 program (Jaimeson, D.G., Ramji, K.V., Neary, T., \& Baxter, T., 1993):

1) The duration of the word preceding a stuttered word within the same sentence (BSTUT).

2) The duration of the same word in the corresponding nonstuttered sentence (BNSTUT).

3) The duration of the word following a stuttered word within the same sentence (ASTUT).

4) The duration of that same word in the corresponding nonstuttered sentence (ANSTUT).

A total of 144 samples were obtained. A two-tailed $\underline{t}$ test was run at the .05 level of confidence to determine significance between the BSTUT/BNSTUT and ASTUT/ANSTUT word pairs. Results yielded a significant difference between the durations of BSTUT and BNSTUT $(P=.017)$. Conversely, analysis of the difference between ASTUT and ANSTUT revealed no significant difference in durations $(P=.47)$. 


\title{
A STUDY OF THE DURATION OF WORDS SURROUNDING A MOMENT OF STUTTERING
}

by

JENNIFER DAWN PETERSON

A thesis submitted in partial fulfillment of the requirements for the degree of

\author{
MASTER OF SCIENCE \\ in \\ SPEECH COMMUNICATON : \\ SPEECH AND HEARING SCIENCE
}

Portland State University

1995 


\section{ACKNOWLEDGMENTS}

I would like to extend a special thanks to Dr. Tetnowski who provided constant encouragement and assistance throughout this study. His talent and knowledge of the field provided me with tremendous insight into the research process.

In addition, I would like to thank Mary $T$. Withers for participating on my committee and helping recruit subjects. Thanks go to Dr. Paul and Dr. Oshika for their participation on my committee and assistance with editing. A heartfelt thanks goes to Jan Young and Heidii Roberts who invested their own time in conducting reliability and to Eugene Eneking who assisted me with the statistical analysis.

I would like to express my appreciation to all the subjects who agreed to take part in this study. Their willingness to devote time to this project made it all possible.

Many thanks are given to all of my family members (especially my grandmother) for their love, support, encouragement and patience while completing this study.

Finally, I would like to thank my husband, John, who volunteered a helping hand, an open heart, a sense of humor, and an enthusiasm for life that could never be matched. 
TABLE OF CONTENTS

ITEM

PAGE

ACKNOWLEDGEMENTS . . . . . . . . . . . . . . . . . i ii

LIST OF TABLES . . . . . . . . . . . . . . . . . vi vi

CHAPTER I: INTRODUCTION . . . . . . . . . . . 1

Statement of Purpose . . . . . . . . . . . 2

Definition of Terms . . . . . . . . . . . . 3

CHAPTER II: REVIEW OF THE LITERATURE . . . . . . . . 5

Definitions of stuttering . . . . . . . . . 5

Treatment Effects on Stuttering . . . . . . . 7

Perceptual Studies of Stuttered Speech . . . . . 11

Physiological Characteristics of Stuttered Speech . 14

Acoustical Characteristics of Stuttered Speech . . 16

Studies of Adaptation . . . . . . . . . . . 18

Effects of Syntactic Boundaries on Stuttered Speech 21

Comparison of Current study to others . . . . . 23

Summary . . . . . . . . . . . . . . 25

CHAPTER III : METHODS . . . . . . . . . . . . 27

Subject Selection . . . . . . . . . . . . 27

Subject Description . . . . . . . . . . . 27

Data Collection Procedures . . . . . . . . 28

Analysis Technique . . . . . . . . . . 29

Reliability . . . . . . . . . . . . 31 
CHAPTER IV : RESULTS AND DISCUSSION • • • • • • • • • 33

Results . . . • . . • . . . . . . . . . 33

Analysis . . . . . . . . . . . . . 33

Statistical Results . . . . . . . . . 35

Intra-Rater Reliability . . . . . . . . . 36

Inter-Rater Reliability . . . . . . . . . 37

Discussion . . . . . . . . . . . . . . 37

CHAPTER V : SUMMARY AND IMPLICATIONS . . . . . . . . . . 40

Summary . . . . . . . . . . . . . . . . . 40

Implications . . . . . . . . . . . . . . 42

Clinical . . . . . . . . . . . . . 4 42

Research . . . . . . . . . . . . 43

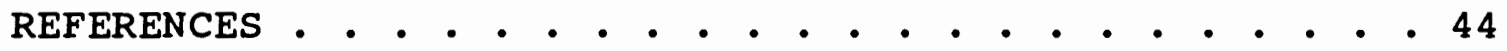
APPENDICIES

A SUBJECT CONSENT FORM . . . . . . . . . . . . 47

B STUTTERING SEVERITY INSTRUMENT . . . . . . . . 49

C SENTENCES FOR PHONETIC INVENTORY . . . . . . 51 


\section{LIST OF TABLES}

TABLE

PAGE

I Biographical Information for Each Subject . 28

II Durations of BSTUT/BNSTUT and ASTUT/ANSTUT

Word Pairs in Milliseconds for all subjects . • . . . . . . . . . . 34

III T-Test of the Mean Differences in Milliseconds for $\mathrm{B}-\mathrm{BN}$ and $\mathrm{A}-\mathrm{AN}$. . . . . . . . 36

IV Intra-Rator Reliability Results of $10 \%$ of the Words Obtained in Milleseconds . . . . 36

$\mathrm{V}$ Inter-Rator Reliability Results of $10 \%$ of the Words Obtained in Milleseconds . . . . 37 
CHAPTER I

INTRODUCTION AND STATEMENT OF PURPOSE

INTRODUCTION

In the past, researchers have struggled to find a definition that accurately defines stuttering. Wingate (1969) has formulated a definition that is most accepted by the research population today. His definition states that stuttering is the "disruption in verbal expression, which is characterized by involuntary, audible or silent, repetitions or prolongations in the utterance of short speech elements, namely sounds, syllables, and words of one syllable" (p.488). Interestingly, individuals can identify a person who "stutters" versus a person who is normally disfluent even if stuttered portions have been deleted from a taped sample of speech (Wendhal and Cole, 1961). What specifically is it that provides a listener with the ability to identify a stutterer from a nonstutterer?

Several studies in the past have examined the concept of adaptation (Klouda \& Cooper, 1987, Prins \& Hubbard, 1990, and Prins \& Hubbard 1992) which is defined by Prins and Hubbard (1990) as the phenomenon in which a stutterer becomes more fluent during repeated oral readings of the same material. Findings of such studies have shown that increases in fluency during adaptation result from temporal 
changes in the speech of stutterers. This might indicate that in order for stutterers to increase fluency, they must practice slowing their rate to gain motor control over their speech.

Various treatment techniques for increasing fluency such as delayed auditory feedback (DAF), choral reading, or prolongation of speech focus on increasing the duration of words to promote fluency. Viswanath (1987) speculates that stutterers will increase durations of words which fall in various positions around a stuttered moment. In other words, he feels that stuttering may be the result of altered temporal speaking patterns.

Until this point, none of these studies examined the differences in temporal characteristics for untreated stutterers in words surrounding a moment of stuttering. It is important to determine whether or not stutterers alter the duration of their speech when they stutter versus when they do not stutter to determine what may be influencing the ability to become fluent.

\section{STATEMENT OF PURPOSE}

The purpose of this study is to examine the durations of words surrounding a moment of stuttering. More specifically, this study seeks to determine whether or not a significant difference exists between the duration of words surrounding a stuttered word and words surrounding the same word when it was produced fluently. Examining the words 
surrounding a stuttered episode versus the same words in a fluent episode will help determine whether or not a stutterer alters some durational characteristic of their speech. Should an alteration in the duration of words occur, it would be important to determine whether or not that change affects the ability to become fluent. The questions to be addressed include:

1) Is there a durational difference between a word preceding a stuttered word and the duration of the same word in a corresponding nonstuttered sentence?

2) Is there a durational difference between a word following a stuttered word and the duration of the same word in a corresponding nonstuttered sentence?

\section{DEFINITION OF TERMS}

The following terms have been used throughout the text of this thesis. Definitions are provided to assist the reader in the comprehension of these terms.

1) Stuttering: The "disruption in verbal expression, which is characterized by involuntary, audible or silent, repetitions or prolongations in the utterance of short speech elements, namely; sounds, syllables, and words of one syllable" (Wingate, 1969 p.488).

2) Adaptation: The phenomena in which a stutterer becomes more fluent during repeated oral readings of the same material (Prins \& Hubbard, 1990).

3) Syntactic Boundaries: Clauses marked by variations in 
the "prosodic structure of the speech wave, including fallrise patterns of [fundamental frequency] and timing effects such as pausing at the syntactic boundary and segmental lengthening of clause-final words" (Klouda and Cooper, 1987 p. 264) .

4) BSTUT: The duration of the word preceding a stuttered word within the same sentence.

5) BNSTUT: The duration of the word preceding the corresponding nonstuttered word in the same sentence. 6) ASTUT: The duration of the word following a stuttered word within the same sentence.

7) ANSTUT: The duration of the word following the corresponding nonstuttered word in the same sentence.

8) Stuttering severity Instrument (SSI): An assessment instrument developed by Riley and Riley (1983) used to analyze the severity of stuttering. Measurements taken to determine severity of stuttering include: a) frequency of dysfluencies, b) estimated length of three longest stuttering occurrences, and c) number of physical concomitants exhibited.

9) Disfluent: Non-fluent speech utterances of persons who do not stutter or non-fluent non-stuttered speech utterances of persons who do stutter (Ham, 1990).

10) Dysfluent: The stuttered speech of persons who do not typically stutter or the stuttered speech of persons who do stutter (Ham, 1990). 
CHAPTER II

REVIEW OF THE LITERATURE

\section{Definitions of stuttering}

Searching for a definition of stuttering has been the endeavor of many researchers, however, difficulties have occurred since so little is understood about this speech disorder. Van Riper (1971), for instance, points out that stuttering occurs when temporal patterning of speech is interrupted. This disruption can manifest itself as prolongations, repetitions, gaps, or insertions. Thus, all individuals have experienced stuttering at one time in their lives. However, not everyone labels themselves as having the disorder of stuttering. The definition formulated by Van Riper, therefore, states that "a stuttering behavior consists of a word improperly patterned in time and the speaker's reactions thereto" (p.15).

Perkins, (1990) took a different approach to defining stuttering. The premise held by Perkins is that stuttering is what actually occurs at the production of speech rather than what the listeners perceive. The speaker, therefore, becomes frustrated as speech is uncontrollably disrupted. This concept lead Perkins to a definition of stuttering stating that "stuttering is the involuntary disruption of a continuing attempt to produce a spoken utterance" (p.376). 
Johnson (1967) felt it was important to keep in mind, while designing his definition of stuttering, that stutterers are human and experience many feelings as a result of their speech. These feelings are elicited by the listener's reactions to the stuttered speech. The reactions of the listener, therefore, cause the speaker to selfevaluate and imagine various consequences. With these concerns taken into consideration, Johnson defined stuttering in the following manner: "stuttering is what occurs when the speaker (1) expects to stutter, (2) dreads doing it, (3) and reacts negatively" (p.240). This reaction occurs not only by anticipating what is about to occur, but also by attempting to avoid being dysfluent. The result of this reaction is disrupted speech. If stutterers are actually able to anticipate a stuttered moment, they may be able to alter conditions of the word preceding the occurrence of stuttering resulting in fluency. According to williams (1957), stuttering too often is viewed as an "entity" within a person that causes a person to become dysfluent. In order to overcome this perception of stuttering, williams states that it is important to look at speech as a whole rather than at stuttering in and of itself. Williams suggests that treatment should focus on helping the client define and describe what he is doing in order to discover what is causing the event labeled as "stuttering" and to discuss how this differs from the speech 
of "normal speakers."

The authors of these definitions were each searching for a way to define "stuttering" in the most descriptive way. These definitions of stuttering, although varying in content, do take into consideration various perceptual characteristics which are the foundation for many research projects in the area of dysfluent speech.

\section{Treatment Effects on stuttering}

In a study conducted by Wendhal and Cole (1961), the perceptually fluent speech of stutterers was analyzed to determine if other aspects of the stutterer's speech are also altered. The purpose of this study was to find out whether or not subjects with an untrained ear could identify a stutterer from a nonstutterer by listening to tapes where the portion of stuttered speech was removed from both recordings. Further study included an analysis of rate, rhythm, and stress in the speech of each group which was also made by subjects with untrained ears. Following review of the tapes, the subjects were able to differentiate the persons who stuttered from those who did not stutter despite the fact that the words that were stuttered on were dubbed out of each tape. Furthermore, results indicate that stutterers exhibited abnormal rates, more strain, and less rhythm in their fluent speech patterns. This indicates that temporal differences may exist between the speech of stutterers and nonstutterers. Wendhal and cole, therefore, 
agree with williams (1957) in that they find it necessary to focus treatment of stuttering on modifying all aspects of speech rather than focusing on the "stuttered block" itself. Although the researchers found perceptual differences in rate, rhythm, and stress, the study neglects to scientifically measure what exactly provides the listener with the ability to detect the speech of stutterers from that of nonstutterers.

The effects of treatment on the acoustical aspects of stuttered speech have also been addressed by various researchers. One such study was conducted by Metz, Onufrak, and Ogburn (1979). Subjects were involved in a six week treatment program based on a Van Riper treatment approach (Van Riper, 1973). This approach comprised of having the client a) analyze his stuttering, b) implement strategies to increase fluency, c) carry-over or generalize these skills. Results show that stuttering frequency significantly decreased following treatment. Reading rates did decrease, however, this decrease was not significant. The researchers point out that the slight decrease in reading rates could be accounted for in that treatment strategies altered overall speaking rate. In addition, significant increases were found in vowel duration and voicing during stop consonants. Results of this study indicate that temporal characteristics appear to play a significant role in the increase of fluency. 
Metz, Samar, and sacco (1983) also described the acoustical characteristics of stuttered speech. An analysis of acoustical features was conducted prior to and following employment of the Van Riper therapy program described in the previous study (Metz et al., 1979). Results of this study showed identical findings of the previous study, however, additional results were found indicating that prior to therapy, a positive correlation existed between silence in the voiced stop consonant intervocalic interval and the frequency of stuttering. The researchers also found that the degree to which silence was reduced "was positively related to the magnitude of reduction in stuttering frequency due to therapy" (p. 535). once again, changes in temporal characteristics are credited for establishing a decrease in stuttered speech.

Onslow, Van Doorn, and Newman (1992) conducted a study which was designed to examine the acoustic affects of treatment based on prolongation as a means of enhancing fluency. Acoustic analysis of speech samples were made prior to and following treatment. Results indicated that following this type of treatment, no significant differences occurred in terms of speech rate and acoustic segment measures. However, a significant decrease in the variability of vowel duration and articulation rates did occur. This study, however, was conducted on a population of children and the researchers did not consider whether or 
not results would differ for adults.

Runyan and Adams (1978) conducted a study in which they examined a listener's ability to perceive the speech of successfully treated stutterers from that of partially treated stutterers and nonstutterers. Samples were taken from each group of speakers and the recordings were altered so that any perceived instances of stuttering were spliced out of the samples. Analysis of listener judgements showed that the speech of stutterers, regardless of receiving treatment, was readily distinguishable from the speech of nonstutterers. No acoustical analysis was made, however, to determine what specifically allows the listener to make such judgements.

Metz, Schiavetti and sacco (1990) conducted a study in which they attempted to discover through psychosocial measurements whether or not the naturalness of speech was on a quantitative or purely qualitative continuum. In addition, Metz et al. wanted to analyze the correlation between perceptual judgements of speech naturalness and the acoustical measurements of treated stutterers versus nonstutterers. Results indicated that the speech of nonstutterers was perceived as more natural than the speech of posttreated stutterers. Acoustic measurements demonstrated that the voice onset times, vowel durations, and sentence durations of posttreated stutterers were significantly longer than those of nonstutterers. In 
addition, it was found that speech naturalness fell on a quantitative rather than a qualitative continuum. Since judges were able to perceive the speech of nonstutterers as more natural than that of posttreated stutterers, it is possible that acoustical differences were also present. since sentence durations were found to be significantly longer for posttreated stutterers, it is possible that stutterers increase fluency by lengthening the duration of specific portions of the sentence.

Combined, these studies indicate that treatment approaches focusing on altering speech patterns do have a positive affect on the increase of fluent speech. Acoustic characteristics of stuttered speech have been found to differ from the acoustic characteristics of nonstuttered speech. It has apparently been difficult, however, to determine what exactly is causing the decrease of stuttering. Perhaps, as Williams (1957) suggested, focusing on speech as a whole rather than concentrating on the stuttering event itself is a more desirable approach to examining the results of effective treatment. Perceptual studies of stuttered speech

Prosek and Runyan (1982) conducted a study whose purpose was to measure the accuracy of judges' perceptions of stuttered speech versus nonstuttered speech. It was found that there is a strong correlation between listener judgement and scientific measurement of stuttered speech 
versus nonstuttered speech. Results indicated that the stutterers had slower speaking rates, used more pauses, and demonstrated longer pauses and vowel durations than nonstutterers. In addition, it was found that there is a strong correlation between listener judgement and scientific measurement of stuttered speech versus nonstuttered speech. According to the results, rate of speech and pause durations appeared to be the strongest predictor for listener judgements. These findings support the findings of Wendhal and cole (1961).

A question was posed following results of the study conducted by Prosek and Runyan (1982) regarding the actual reason for the discrepancy between stutterers and nonstutterers perceptual speech characteristics (Prosek \& Runyan, 1987). The researchers speculate that the ability to successfully distinguish treated stutterers from nonstutterers may be attributed to the fact that therapy does not focus on all aspects of stuttering (Runyan \& Adams, 1978). This also supports Williams' (1957) claim. Another rationale offered by the researchers focuses on the idea that treatment of stuttering may actually introduce these perceptual features into the speech of stutterers when attempting to eliminate overt stuttering behaviors. This second explanation was also supported by the findings of Metz, Onufrak, and Ogburn (1979).

The examination of yet another parameter of the 
dynamics of stuttered speech was conducted by Howell and wingfield (1990). The purpose of this study was to determine whether or not the speech of stutterers is less fluent when close in proximity to a stuttered event and if listeners are perceptually sensitive to this change if it does occur. Utterances which had dysfluencies preceded by and followed by speech spans with no audible dysfluencies were used for analyzing. Stuttered portions of the tapes were spliced out of the final tape for analyzing. Results showed that a) listeners were able to separate the experimental group from the control group, b) listeners could determine the type of stutter that occurred (prolongation or repetition), and c) listeners were unable to determine whether the stutter occurred prior to or following the utterance. An acoustic analysis followed the first portion of the study. Results showed that no differences existed between the control group and the experimental group in terms of duration, number of pauses, speech rate, or average intensity over a section. In addition, there were larger differences in the dips and peaks of intensity (modulations) in sections which surrounded repetitions than in sections which surrounded prolongations. The researchers, therefore, determined that a positive correlation exists between modulations and the listeners' ability to discriminate the control group from the experimental group. The same correlation allows the 
listener to separate prolongations from repetitions. Rate also may have aided in the listener's ability to discriminate one group from another, however, the research did not examine this aspect of perception.

Perceptual characteristics of stuttered speech are well defined by researchers such as Van Riper (1971), Perkins (1990), Johnson (1967), and Williams (1957). The characteristics of prolongations, repetitions, pauses, and interjections are how the untrained listener can perceive stuttered speech. Untrained listeners also have the ability, however, to identify a person who stutters from tapes where the stuttering events have been spliced out. This leads to some question as to what specifically causes these perceptual features to exist in dysfluent speech. Physiological characteristics of stuttered speech

Another area of study which focuses on the variations in stuttered speech includes physiological investigation. Zimmermann conducted a study (1980a) in which he attempts to look at stuttering as the result of a disruption of the neuromuscular process involved in speech. Kinematic measurements indicated that stutterers show smaller displacement, lower peak velocities, and longer transition times for lip and jaw movements. Finally, the results of interarticulatory coordination showed that asynchrony was greater for stutterers during specific oral/facial movements. In addition, it was found that there is a 
difference between stutterers and nonstutterers in terms of organizational patterning. zimmermann submits the idea that the various differences found during the study might indicate that the stutterer has learned the behavior of slowing the duration of a production in order to allow for gain control over motor movements. This researcher believes that if this were true, then the slowing of word durations in sentences should allow the stutterer to gain control over his/her motor movements, thus, resulting in increased fluency. Zimmermann's study, however, looked only at syllable production rather than at production at the sentence level.

Zimmermann (1980b) continued his research to give a description of the movements which occur during perceptually disfluent utterances of stutterers. These measurements would include both temporal and spatial aspects exhibited by the movements of the articulators. Following the gathering of data, it was determined that precise repositioning of the articulators occurs prior to the act of speaking. The researcher was unable, however, to determine if these behaviors occur as the result of temporal relationships or the actual initiation and termination of articulatory posturing. In either case, the increase of fluency could be associated with the prolongation of speaking rates. In one case, slowing of speaking rate would allow the speaker to take time to reposition the articulators. In the second 
condition, slowing speech rate would place fewer demands on the neuro-muscular processes involved in speaking.

The studies focusing on the physiological

characteristics of stuttered speech have indicated that temporal changes do take place as a person becomes more fluent. It is speculated that slowing the rate of speech may allow the speaker to regulate the timing of the muscles used for speech and, thus, becomes more fluent. This concept, therefore places high value on the speaker's gaining control over his/her speaking and that rate may be the primary factor for increasing fluency. Acoustical Characteristics of stuttered speech

Acoustical features of stuttered speech have also been examined by researchers. Pindzola (1987) found results supporting the research conducted by Zimmermann (1980a). The Pindzola study consisted of an analysis of acoustic features exhibited in the speech of stutterers versus that of nonstutterers. The data gathered shows that stutterers have a tendency to spend a greater amount of time in static articulatory positions than nonstutterers. This outcome provides additional evidence backing zimmermann's study. In addition, Pindzola speculates that although the "steadystate vocalic portions represent relatively stable vocal tract configurations" the mechanism used for speech production may be temporally disturbed (p. 49). The researchers in this study neglect to look at the influence 
of words surrounding a stuttering event at the sentence level. Here again, however, temporal aspects of the speech mechanism are speculated to be involved in the initiation of stuttering.

Adams (1987) also looked at the acoustic aspect of stuttered speech when he compared the voice onset times (VOT) and segment durations of young stutterers to those of normal speakers. Results indicated voice onset times were slower and the duration of vowels and consonants were longer for children who stutter. In addition, it was found that stutterers varied more in their temporal organization of speech production. These results support Zimmermann's (1980a) findings as well. Although durations were found to be slower for stutterers in this study, the researchers did not compare the fluent speech production of stutterers with that of nonfluent speech utterances.

De Nil and Brutten (1991) took another approach by testing the hypothesis that the increase of external and linguistic time pressure would have different acoustic effects on stutterers and nonsutterers in terms of the variability and duration of the voice onset times. Measurements were taken from the readings of target words. Results showed that when the stuttering children were placed under no time pressure, voice onset times were notably longer than those of nonstutterers. Similar results were found when the children were placed under time pressure, 
however, voice onset times were significantly shorter in duration for both groups when placed under time pressure than when under conditions of no time pressure. Although the difference between stutterer's and nonstutterer's voice onset times were not significant, the voice onset times of stutterers were longer. This may indicate that stutterers need to alter certain temporal characteristics of their speech in order to produce speech fluently. This study, however, was conducted simply at the word level and does not take into consideration the affects surrounding words may have on fluency.

In studying the acoustic characteristics of stuttered speech, researchers (Pindzola, 1987 \& Adams, 1987) have noted that the duration of speech appeared to be longer for those who stutter than for those who are nonstutterers. Temporal changes during fluent speech should, however, be compared to those during nonfluent speech in order to determine what may increase the speaker's ability to produce fluent utterances. Studies of Adaptation

Still another area of study focuses on adaptation. One such study involves measuring various acoustical durations which occur during successive readings in stutter-free and disfluency-free speech (Prins \& Hubbard, 1990). Intervocalic interval, stop-gap, voice onset time, and vowel duration measurements were obtained from adapting, 
nonadapting, and nonstuttering subjects. The results showed that segment durations and relative durations did not alter between the stutterers with high adaptation scores, stutterers with low adaptation scores, and nonstutterers. stutterers were found, however, to have slightly higher phonation rates in the last reading than in the first reading. One explanation the researchers offer for this discrepancy in their prediction is that both fluencyinducing situations and adaption bring about a reduction in the demands on motor-linguistic functioning, however, they each accomplish this in a different manner. In addition, the researchers were unable to explain why the trials in which adaptation occurred appeared perceptually more rhythmic. The researchers in this study state that there are no acoustical changes between adapting and nonadapting stutterers. They looked, however, at the differences between subjects rather than within subjects. One variable they did not consider is whether or not stutterers compensate for fluency within their own speech during adaptation trials.

In an attempt to develop a rationale for the rhythmicsounding speech in the previous study, a follow-up study was conducted (Prins \& Hubbard, 1992). This study focused on examining the consistency of interstress intervals (ISIs) during the fluent speech of people who stutter during adaption trials. Results of this study indicate that no 
increase in ISIs occurred from the first reading to the fifth reading. The researchers, therefore, suggested that the listener's perception of rhythmic speech during fluent productions could just be a function of stutter-free speech rather than a change in ISIs. Findings also indicated that the ISIs of stutterers were more variable in duration than those of nonstutterers. Prins and Hubbard state utterances with ISIs that were longer in duration placed more demand upon the speech motor control process resulting in the variability.

Another approach to studying the concept of adaptation was adopted by Besozzi and Adams (1969). These researchers conducted a study in which they attempted to determine whether or not adaptation occurred more during oral reading practice than during silent reading practice. Results showed that a significant amount of adaptation occurred during both situations. However, a significantly greater amount of adaptation occurred during oral reading practice than during silent reading practice. Although this study does not indicate which prosodic changes account for increased fluency, the results imply that some changes in prosody do occur during adaptation. Oral practice may also allow the subject to regain control of temporal patterning necessary to gain motor control over speaking.

Bruce and Adams (1978) also examined the concept of adaptation. In this particular study, the researchers 
examine the effects of whispered rehearsal on adaptation. They also attempt to determine whether reading aloud effects adaptation more than whispered reading. Results indicated that a significant amount of adaptation occurred in both reading situations. Again, significantly more adaptation occurred during the oral readings than during whispered readings. These results emulate the findings of Besozzi and Adams (1969)

These researchers have attempted to clarify what exactly allows for adaptation to occur in some speakers (Besozzi \& Adams, 1969, Bruce and Adams, 1978, Prins \& Hubbard,1990, and Prins \& Hubbard 1992). Since changes in fluency primarily occurred in situations where readings were performed orally, it would appear that modifications in physiologic and acoustic aspects of speech may be contributing factors. Thus, high adapting speakers may possess a stronger ability to better control the timing of speech musculature when reading than nonadapting speakers. Effects of syntactic Boundaries on stuttered speech

An attempt was made by Klouda and Cooper (1987) to address how syntactic clausal boundaries and speech timing effect the frequency of stuttering. Two separate studies were conducted to determine whether or not a relationship exists "between stuttering and the constituent structure of an utterance" (p.263). The first experiment conducted was designed to determine whether or not a stuttering episode is 
more likely to occur on the first word of a major syntactic boundary. Results indicate that the presence of a major syntactic boundary did not increase the occurrence of stuttering.

The second study conducted by these researchers (Klouda \& Cooper, 1987) was expanded to include an acoustical analysis of the affects a syntactical boundary has on the duration of speech characteristics. The purpose of this portion of the study was to first determine whether or not the duration of a word increases when it falls in the final position of a clause. Second, the researchers hoped to find out whether or not a pause follows a word in clause-final position. The outcome of the pause duration analysis shows that "stutterers are more likely to pause at major syntactic boundaries than at the same location in a sentence without a major boundary" (p.270). Analysis of word durations indicate that the duration of a target word is longer when it occurs prior to a major syntactic boundary. This was found to be true for both fluent and nonfluent speech. The researchers also noted that words were slightly more lengthened during fluent speech. Finally, it was determined that stuttering did not occur more frequently on words preceding or following a major syntactic boundary than on the same word when not in the context of a major syntactic boundary .

Based on the findings of the two studies, the 
researchers concluded that the mechanisms involved in syntactic planning and processing are independent of those involved in stuttering (Klouda \& Cooper, 1987). These results contradict the findings of Zimmermann (1980a), Zimmermann (1980b), Pindzola (1987), and Prins and Hubbard (1992). The results show that major syntactic boundaries do not affect fluency, however, the researchers did not look at other temporal characteristics of words surrounding stuttered words.

comparison of current study to others

A study examining acoustic-temporal aspects of the clausal utterances of stutterers and nonstutterers was the main focus of a study conducted by Viswanath (1989). Subjects were asked to read a short story five times in succession. Both global and temporal analysis were conducted from the sample of readings obtained. The goal of the global analysis was to examine the difference between stutterers and nonstutterers in terms of temporal reorganization of clausal utterances during adaptation. In addition, temporal reorganization of clausal utterances with and without stuttering events were also examined in situations where adaptation occurred. Analysis explored the effects of a stuttering event on the durational characteristics of words close to and distanced from the stuttered word. Measurements were taken from clauses which a) contained a stuttered event in the first reading and were 
completely fluent without distortion during the last four readings, b) contained fluent and undistorted productions during all five productions on the last word of the preceding utterance and on the first word of the following utterance, and c) contained completely fluent and undistorted productions from the matched control group. Results of the global analysis showed that stutterers actually increase speaking rates while increasing fluency. Thus, the researchers conclude that longer articulation rates and more frequent pausing are more likely functions of stuttered speech, not fluent speech. In addition, the researchers concluded that fluency-enhancing conditions are not necessarily based on the slowing of speech rates. Local analysis indicated that stutterers tend to increase the duration of a word that was stuttered on, but was later produced fluently. Further analysis showed that the duration of the words preceding and following a stuttered word are prolonged although this increase is not significant. The researchers, therefore, concluded that "stutterers are likely to have longer durations than normal in various locations around a stuttering event" (p.261). The current study also attempts to measure the duration of words surrounding fluent speech versus nonfluent speech. studying the durational differences between stutterers and nonstutterers is important, however, it is also important to control for the effects treatment may have on increasing 
fluency. Examining the durational characteristics of stutterers who have not received treatment will aid in the understanding of what stutterers do to increase fluency. Treatment of stuttering often focuses on altering the duration of speech in some manner in increase fluency. Those who have received treatment will most likely use these strategies while speaking whereas those who have not been in treatment most likely will not consciously alter durations. Summary

Up to this point, studies have provided a great deal of information about stuttering, however, there is a lack of information regarding the acoustical difference in stuttering events occurring in the speech of non-treated stutterers. The study conducted by Viswanath (1989) attempts to examine the durational characteristics of words surrounding a stuttered word versus those produced fluently during the process of adaptation. While it is important to study the difference of the speech of stutterers versus nonstutterers, it is also important to examine the speech of stutterers who have not received treatment. The focus of the current study, therefore, is to determine whether or not the temporal characteristics of words surrounding a moment of stuttering differ from those surrounding a fluent moment of speech for non-treated stutterers. Analysis will only be performed on words not surrounded by syntactic barriers. Syntactic barriers, as defined by Klouda and Cooper (1987), 
will be those clauses marked by variations in the "...prosodic structure of the speech wave, including fallrise patterns of [fundamental frequency] and timing effects such as pausing at the syntactic boundary and segmental lengthening of clause-final words" (p.264). 
CHAPTER III

METHODS

\section{Subject selection}

Three subjects age 16 and older were used in this study. These subjects were contacted by phone from a list of people who have been in contact with Portland state University's speech and Hearing clinic concerning stuttering. Subjects were required to fill out a consent form (see Appendix A) prior to conducting the study. Severity of stuttering was determined by administering the Riley stuttering Severity Instrument (SSI) (Riley and Riley, 1983) at the Portland State University Speech and Hearing Clinic (see Appendix B). The subjects had to perform at a severity rating of at least "moderate" following administration of the SSI. In addition, a hearing screening was conducted to assure that hearing was within functional limits for conversation. The subjects did not have any other speech or language disorders. In order to qualify for the study, subjects were to have never had stuttering treatment or to not have had stuttering treatment for at least four years.

Subject Description

Three subjects agreed to participate in the study. The population comprised of two males and one female. 
Information reguarding the subject's ages, previous treatment, and severity rating of stuttering as determined by the SSI (Riley and Riley, 1983) are listed in Table I. TABLE I

BIOGRAPHICAL INFORMATION FOR EACH SUBJECT

$\begin{array}{ccccc}\text { Subject } & \text { Age } & \text { Years Since Treatment } & \text { Severity of Stuttering } \\ \text { PG } & 53 & 5 & \text { Moderate } \\ \text { AN } & 48 & \text { Never } & \text { Very Severe } \\ \text { NG } & 16 & 4 & \text { Moderate }\end{array}$

Data collection Procedures

Subjects were seated at a distance of 20 centimeters from a uni-directional Neumon $\mathrm{U} 67$ microphone and were asked to read a list of 83 sentences twice in their "normal speaking voice" without making any adjustments. The readings were selected from a combination of lists located in Fairbanks (1940) (see Appendix C). Sentences were selected from these lists due to the fact that they represent each sound of the English language in the initial, medial, and final position of words. A thirty minute break was taken between the two readings. The subjects were audio recorded on a seven and a half millimeter Technics 1506 half-track reel to reel tape as they read the sentences. Following the collection of data, the researcher and three judges listened to the recordings and marked the script for all stuttered words from each of the readings. Sentences which contained a word that was stuttered on in the first reading and not in the second or in the second reading but not in the first were used for analysis. 
Sentences that were not used for analysis include those which: a) contained a stuttered word at the beginning or end of a syntactic boundary, b) contained a stuttered word at the beginning or end of a sentence, c) contained a stuttered word that is preceded or followed by a word occurring at the beginning or end of a natural syntactic boundary or sentence, and d) contained a stuttered word that is preceded or followed by another stuttered word. Selection of these criteria was made in order to reduce the effects of additional temporal alterations in the samples.

\section{Analysis Technique}

Analysis of the sentences involved measuring the duration of the words prior to and following a stuttered word and measuring the duration of the corresponding words in the nonstuttered episode. Temporal analysis of these words was be made via the Canadian speech Research Environment Program (CSRE) version 4.2. (Jamieson, Ramji, Nearey, and Baxter, 1993). Input to CSRE was through the tape recordings. Prior to the tape recording of readings, a 1,000 hertz tone was presented on Channel 1 of the recording for calibration purposes. Further recordings of the readings were then made on Channel 2 of the same tape. The readings were then digitized through a Tucker-Davis Technologies DDI A/D conversion board and were run through the CSRE program at 40,000 samples per second in order to produce oscillographic traces. Prior to analysis, the 
signal was filtered at a level of 10,000 Hertz (low-pass) on a Wavetek 752A Brickwall Filter. Using auditory and visual cues, the sentences were then broken down into single word units. The computer cursor was then moved to either side of the apparent word units and the oscillograph was magnified to better view the quasiperiodic and periodic wave forms which constitute words. Voice onset and offset of words was determined by locating the first negative peak of the quasiperiodic wave form. For unvoiced phonemes, onset and offset of speech sounds was determined by examining the doubling effect of the amplitude of the noise signal. To insure no sounds were omitted or inaccurately included during the marking process, the words were then played back over loudspeakers. After it was determined that the words were accurately marked by the cursors, the duration of the words in milliseconds was displayed by the CSRE and saved on a 3.5" disk for further comparison.

Temporal measurements taken include: a) the duration of the word preceding a stuttered word within the same sentence (BSTUT), b) the duration of the same word in the corresponding nonstuttered sentence (BNSTUT), c) the duration of the word following a stuttered word within the same sentence (ASTUT), and d) the duration of that same word in the corresponding nonstuttered sentence (ANSTUT). The differences between the measurements of BSTUT minus BNSTUT and ASTUT minus ANSTUT were then calculated. These 
differences were recorded to determine statistically whether or not the differences were significant. Analysis of these measurements was made by conducting a two-tailed paired t-test. This analysis technique was used in order to determine whether or not there was a significant difference in the durational relationship between words that surround a stuttered word and words that surround the same word when it was produced fluently. This relationship would provide further information into the characteristics of stuttered speech.

\section{Reliability}

Inter-judge reliablilty for the identification of stuttering was obtained through consensus agreement with a graduate student in speech-language pathology and a supervisor from the Portland State University's speech and hearing program. Both judges had extensive experience in identifying and treating stuttering disorders. The judges were asked to listen to the recorded tape samples and to mark all of the stuttered words on a duplicated script of the Fairbanks Sentences list. Judges were asked to mark words stuttered in the first sentence with a \#1 and words stuttered in the second reading with a \#2. The judges were instructed to use the rules for the SSI for determining stuttered words when marking their scripts. According to the SSI, stuttered words to be counted include:

1. Whole-word repetitions of one syllable words. 
2. The repetition of a sound or syllable within a word.

3. The audible prolongation of the first sound in a word.

Consensus agreement among the judges was reached at $100 \%$ accuracy prior to using any words for the sample. If agreement was not reached for a word, it was taken out of the sample.

Reliability for the determination of word duration was conducted by having a Ph.D. level speech-language pathologist with extensive experience in both stuttering and acoustic analysis repeat the experimental procedure on ten percent of the samples. The same methodology was used for determining the beginning and end of words. 
CHAPTER IV

\section{RESULTS AND DISCUSSION}

RESULTS

The purpose of this study was to determine whether or not there was a significant difference between the duration of words surrounding a stuttered event with stutterers who have not received treatment. More specifically, the purpose was to examine the duration of the words prior to and following a stuttered word and the duration of the corresponding words in a matched nonstuttering environment.

\section{Analysis}

Following the determination of words to be analyzed using the criteria previously described, a list of words was compiled. The variables measured were: a) the duration of the word preceding a stuttered word within the same sentence (BSTUT), b) the duration of the same word in the corresponding nonstuttered sentence (BNSTUT), c) the duration of the word following a stuttered word within the same sentence (ASTUT), and d) the duration of that same word in the corresponding nonstuttered sentence (ANSTUT). Thirty-six words were stuttered, which meant that thirty-six words were analyzed prior to the stuttered word and thirtysix words were analyzed following the stuttered word. In 
addition, the exact word from a nonstuttered sample was also analyzed. Thus, a total of 144 words were analyzed. The resulting durations of the BSTUT/BNSTUT and ASTUT/ANSTUT word pairs are listed in Table II.

TABLE II

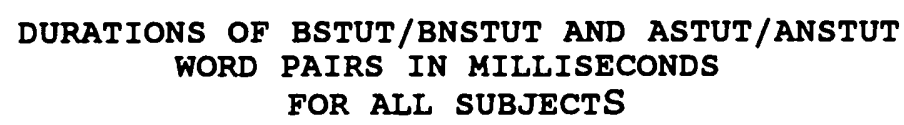

\section{Subject Sentence $t$ Word Analyzed}

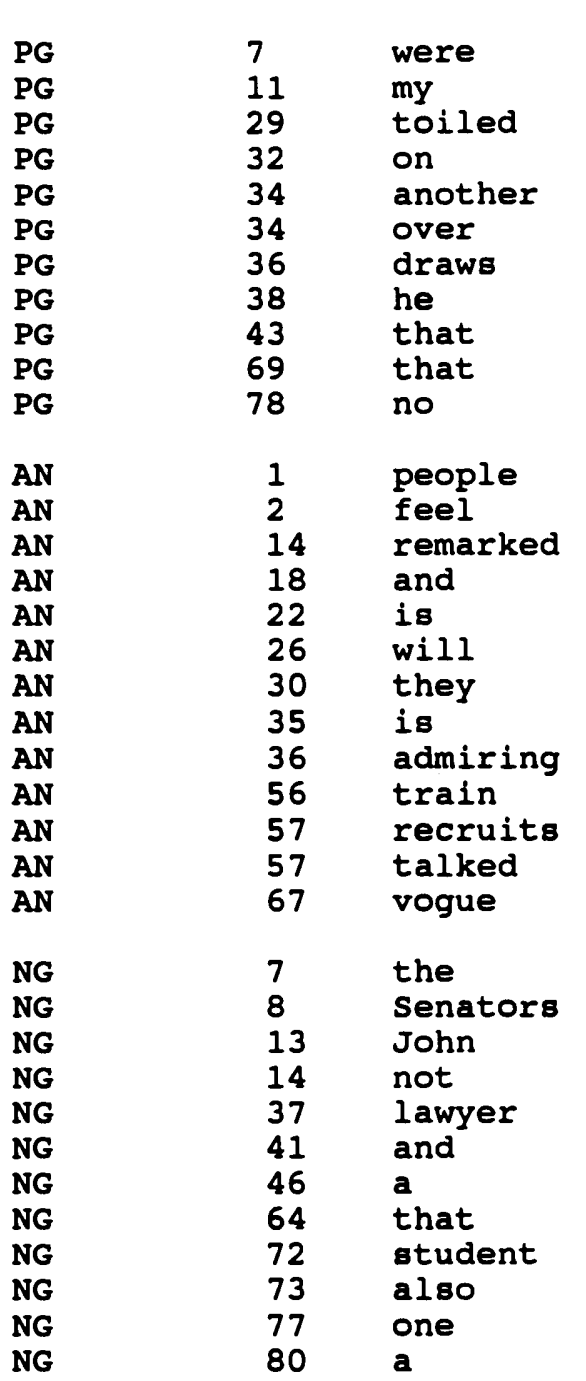

\begin{tabular}{lll}
\multicolumn{3}{c}{ Duration word Analyzed } \\
Bstut & Bnstut & \\
160.8 & 134.2 & to \\
625.3 & 206.6 & Gus \\
716.9 & 561.1 & in \\
363.9 & 470.3 & the \\
375.3 & 332.2 & is \\
394.6 & 465.8 & September \\
590.9 & 503.6 & crowds \\
522.8 & 134.1 & placed \\
165.2 & 272.9 & was \\
287.9 & 109.0 & would \\
324.6 & 364.2 & to
\end{tabular}

$\begin{array}{lll}336.5 & 312.2 & \text { that } \\ 404.1 & 486.8 & \text { are }\end{array}$

Duration

Astut Anstu

107.2131 .5

707.1646 .6

$147.9 \quad 198.1$

$131.3 \quad 121.1$

224.6220 .1

$834.4 \quad 650.5$

$569.7 \quad 629.3$

542.1443 .1

$182.1 \quad 196.8$

$275.0 \quad 180.3$

$308.0 \quad 448.7$

$182.4 \quad 83.7$

$147.1 \quad 174.6$

that $\quad 123.3145 .2$

and 165.7165 .0

in $\quad 172.6155 .1$

it $\quad 147.1150 .2$

the $89.1 \quad 59.4$

with $234.0 \quad 311.6$

from $\quad 242.7 \quad 189.8$

the $\quad 64.1 \quad 55.6$

and $\quad 138.3138 .8$

night $\quad 343.0 \quad 443.6$

be 209.5204 .0

of $\quad 125.0 \quad 127.1$

pleasure $\quad 472.4 \quad 454.9$

across $\quad 397.1388 .1$

too 151.0149 .9

held $\quad 384.6336 .0$

ran $\quad 349.9306 .6$

yam $\quad 497.0 \quad 584.6$

is $\quad 253.7 \quad 152.4$

not 255.4 210.3

by $\quad 197.4266 .8$

a 86.186 .3

old $\quad 175.5 \quad 151.7$

statistical results of these durations will be

discussed further to address the following questions: 
1) Is there a significant durational difference between a word preceding a stuttered word and the duration of the same word in a corresponding nonstuttered sentence?

2) Is there a significant difference between a word following a stuttered word and the duration of the same word in a corresponding nonstuttered sentence?

\section{Statistical Results}

The first question addressed by this researcher was: Is there a significant difference between the word preceding a stuttered word (BSTUT) in the same sentence and the duration of the same word in the corresponding nonstuttered sentence (BNSTUT)? Initially, the differences between the word pair BSTUT/BNSTUT were calculated. Statistical analysis of the difference between the word pairs BSTUT and BNSTUT $(n=36)$ were run using a two-tailed paired $t$ test at a confidence interval of .05. Results of this analysis yielded a P-value of .017 (see Table III). This indicates that there is a statistically significant difference between BSTUT and BNSTUT.

The second question addressed by this researcher was: Is there a significant difference between the word following a stuttered (ASTUT) word in the same sentence and the duration of the same word in the corresponding nonstuttered sentence (ANSTUT)? Here again, the difference between ASTUT and ANSTUT was calculated and a two-tailed paired $t$ test was conducted at a confidence level of .05 (see Table III). A 
P-value of .47 was obtained which indicates that there is not a significant difference between ASTUT and ANSTUT at the confidence level of .05.

TABLE III

T-TEST OF THE MEAN DIFFERENCES IN MILLISECONDS FOR B-BN AND A-AN

\begin{tabular}{llcclll} 
Variable & N & Mean & StndDev & SE Mean & T & P-Value \\
\hline B-BN & 36 & 57.7 & 138.0 & 23.0 & 2.51 & 0.017 \\
A-AN & 36 & 7.7 & 63.7 & 10.6 & 0.73 & 0.47
\end{tabular}

Intra-rater Reliability

Intra-rater reliability measures were obtained by the researcher via repetition of the methodology previously described on $10 \%$ of the samples listed in Table II. A Pierson product moment correlation coefficient yielded a value of .943 indicating high intra-rater test-retest reliability. Durational results of this portion of reliability are listed in Table IV.

TABLE IV

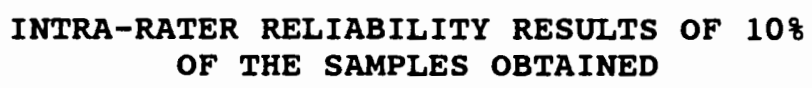

Subject Sentence \# Word Analyzed Duration/1st Trial Duration/2nd Trial

$\begin{array}{lrlrr}\text { PG } & 7 & \text { were } & 160.8 & 159.6 \\ \text { PG } & 11 & \text { Gus } & 707.1 & 436.8 \\ \text { PG } & 36 & \text { crowds } & 569.7 & 539.1 \\ \text { PG } & 43 & \text { that } & 165.2 & 173.3 \\ \text { PG } & 69 & \text { that } & 287.9 & 312.0 \\ & & & & \\ \text { NG } & 8 & \text { pleasure } & 472.4 & 510.5 \\ \text { NG } & 41 & \text { ran } & 306.6 & 301.7 \\ \text { NG } & 46 & \text { yam } & 584.6 & 565.0 \\ \text { NG } & 77 & \text { a } & 86.3 & 85.5 \\ & & & & \\ \text { AN } & 14 & \text { that } & 145.2 & 144.0 \\ \text { AN } & 22 & \text { is } & 155.1 & 728.3 \\ \text { AN } & 36 & \text { admiring } & 744.1 & 87.4 \\ \text { AN } & 56 & \text { the } & 64.1 & 319.1 \\ \text { AN } & 57 & \text { talked } & 446.1 & 1\end{array}$




\section{Inter-rater Reliability}

Reliability measures were taken by having a Ph.D. level speech-language pathologist with extensive experience in the diagnosis and treatment of stuttering analyze the duration ten percent of the words obtained. Measurements were taken using the same methodology previously described. Results of the reliability portion of this study are listed in Table $v$.

\section{TABLE V}

INTER-RATER RELIABILITY RESULTS OF $10 \%$ OF THE WORDS OBTAINED

\begin{tabular}{|c|c|c|c|c|}
\hline Subject & Sentence \# & Word Analyzed & Duration/Professor & Duratio \\
\hline PG & 11 & my & 625.3 & 1136.0 \\
\hline PG & 29 & toiled & 716.9 & 586.9 \\
\hline PG & 34 & over & 394.6 & 476.0 \\
\hline PG & 43 & that & 272.9 & 258.5 \\
\hline NG & 7 & of & 127.1 & 121.8 \\
\hline NG & 14 & too & 149.9 & 170.8 \\
\hline NG & 64 & that & 364.7 & 365.3 \\
\hline NG & 72 & not & 210.3 & 273.8 \\
\hline NG & 80 & $\mathbf{a}$ & 314.3 & 302.8 \\
\hline AN & 1 & people & 336.5 & 492.9 \\
\hline AN & 30 & they & 130.0 & 133.4 \\
\hline AN & 35 & with & 311.6 & 367.7 \\
\hline AN & 35 & is & 167.6 & 139.7 \\
\hline AN & 67 & be & 204.0 & 212.8 \\
\hline
\end{tabular}

Reliability measures were analyzed by calculating a pierson product moment correlation coefficient. Results yeilded a coefficient of .854 indicating that there is high inter-rater test-retest reliability.

\section{DISCUSSION}

Data gathered from this study was used to determine whether or not there was a significant difference between the duration of words surrounding a word that was stuttered 
and the same word in the corresponding nonstuttered event. Results indicated that there is a significant difference between the word prior to the stuttered event and the corresponding word in the nonstuttered event. Post-hoc analysis of these word pairs conducted by visual inspection shows that words occurring prior to the stuttered word in a sentence were on average longer in duration that those occurring prior to the corresponding nonstuttered word (see Figure 1). This may suggest that a person who stutters has the ability to anticipate a stuttering event and, in that anticipation, prolongs the preceding word. Conversely, the difference between the word following the stuttered event and the corresponding word in the nonstuttered event did not approach the level of significance.

Durational studies of stuttered speech compared to nonstuttered speech allow researchers to substantiate the altered speech characteristics found in perceptual studies of the speech of stutterers (Prosek \& Runyan, 1982; Prosek \& Runyan, 1982; Howell \& Wingfield, 1990). Results of the current study indicate that a change in durational characteristics does occur on words surrounding a stuttered word versus those surrounding the same word produced fluently for non-treated stutterers. It is interesting to note, however, that an increase in word durations were found prior to the word that was stuttered rather than on the corresponding word in the nonstuttered event. These results 
are similar to the results found by Viswanath (1989).

According to the results of the viswanath study, there is an increase in the words surrounding a stuttered word.

Viswanath found that an increase in the word prior to a stuttered word approached significance $(P=.07)$, but did not actually reach significance at the .05 level of confidence. According to the results of the current study, non-treated stutterers tend to alter the word prior to a stuttered event in a similar manner as those who may have received treatment. 


\section{CHAPTER V \\ SUMMARY AND IMPLICATIONS \\ SUMMARY}

The purpose of this study was to determine if there was a significant difference in the duration of words surrounding a stuttered word and those surrounding a nonstuttered word. More specifically, the purpose was to examine the duration of the words prior to and following a stuttered word and the duration of the corresponding words in the nonstuttering episode. In designing this study, the following questions were to be addressed:

1) Is there a significant difference between the word preceding a stuttered word in the same sentence and the duration of the same word in the corresponding nonstuttered sentence?

2) Is there a significant difference between the word following a stuttered word in the same sentence and the duration of the same word in the corresponding nonstuttered sentence?

Three subjects age 16 and older were selected from list of perspective clients for the Portland State University Speech and Hearing clinic. The subjects had not received treatment for at least 4 years or more. Subjects read a list of 83 sentences from Fairbanks' sentences for phonetic 
inventory twice with a 30 minute break separating the readings. All readings were taped on reel to reel tapes for analysis. Sentences which contain a word that was stuttered on in the first reading and not in the second or in the second reading but not in the first were used for analysis. The duration of the following word pairs in milliseconds was computed via the CSRE 4.2 program:

1) The duration of the word preceding a stuttered word within the same sentence (BSTUT).

2) The duration of the same word in the corresponding nonstuttered sentence (BNSTUT).

3) The duration of the word following a stuttered word within the same sentence (ASTUT).

4) The duration of that same word in the corresponding nonstuttered sentence (ANSTUT).

A total of 36 samples was obtained for analysis. A two-tailed $t$ test was run at the .05 level of confidence to determine whether or not there was a significant difference between the BSTUT/BNSTUT and ASTUT/ANSTUT word pairs. Results showed that there was a significant difference between the durations of BSTUT and BNSTUT $(P=.017)$ at the .05 confidence interval. In addition, it was noted that, on average, the word preceding the stuttered episode was longer in duration than the corresponding word in the nonstuttered episode. Conversely, analysis of the difference between ASTUT and ANSTUT revealed that although differences in 
durations did occur $(P=.47)$, these differences did not reach the point of significance at the .05 level of confidence. Further investigation of the differences between ASTUT and ANSTUT showed that the majority of words following the stuttered episode were longer in duration than the words in the nonstuttered counterpart.

\section{IMPLICATIONS}

\section{clinical}

One of the most significant clinical implications of this study is that treatment strategies often focus on increasing the production of words to promote fluency. According to the results of the current study, however, stutterers are more likely to increase the production of a word prior to a dysfluency. This may indicate that a stutterer has the ability to anticipate stuttering and in that anticipation becomes tense and prolongs the word preceding the anticipated stuttered word. Perhaps, then, treatment should not focus on the prolongation of words but rather on the concept of relaxation and "easy onset".

Another clinical implication of the current study is the possibility that treatment should focus on increasing the rate of speaking rather than slowing down the speaker's rate. Results of this study indicated that the word preceding a fluent utterance was more likely to be shorter in duration than a word preceding a nonfluent utterance. Thus, slowing the rate of speaking may be a less effective 
treatment strategy for stuttering than increasing the rate of speaking.

It was noted during collection of data that each speaker had unique characteristics of their stuttered speech. For example, one stutterer was more likely to repeat sounds as in "sssssselling" where as another was more likely to insert interjections such as "um" frequently. One clinical implication drawn from this observation is the idea that stuttering treatment should focus more on the individual needs of each client. The most effective treatment strategy for one client may be "easy onset" while the most effective treatment for another client may be shortening or lengthening word durations.

\section{Research}

The current study focused on three subjects age 16 and older. Further research encompassing subjects of different age groups would help substantiate these findings. In addition, an increase in the number of subjects would give more statistical power to the results of these findings. An additional suggestion for further research would be to control for the fluency of the word prior to BSTUT and the word following ASTUT. In this study, it was noted that at times the word preceding BSTUT or the word following ASTUT was stuttered on. This made it difficult to determine whether or not a change in duration was the result of the word preceding BSTUT or of the stuttered word itself. For 
example, sentence number one reads "Some people reason that seeing is believing." If a stutterer produced the word "that" dysfluently in one reading but not in another, a measurement of BSTUT (in this case "reason") would be used for the study. However, there were times when the word preceding BSTUT (in this case "people") was also stuttered on. The same question arose when examining words in the ASTUT position that were followed by stuttered word. Controlling for the fluency of the word preceding BSTUT and the word following ASTUT would also help substantiate the findings of the current study.

The current study did account for the effects syntactic boundaries may have on durational changes in speaking. The study did not consider, however, variations in stress and classification of words among sentences. Differing stress patterns may effect changes in duration. Changes in word classification from sentence to sentence may change durational patterns as well. For example, production of the word "the" in the sentence "The ball is round" would be different than production of "the" the sentence "please hand me the red ball." Further study should control for these types of variations which may effect the durational patterns of words in a sentence.

As mentioned in the clinical implications, individual differences in the characteristics of stuttering for each subject became very apparent to this researcher during the 
study. An interesting extension of the current study would be to determine whether there is a significant difference among the word pairs for each individual subject. The differences in duration among individual subjects could then be compared to the durational differences found in the combination of all subjects. This would give insight into the possible differences among subjects and how that difference affects the overall results of the combined data. This may also lead to sub-classification of stutterers. Another interesting extension of the current study might be to examine, in relative terms, the difference of word durations based upon differing word lengths. For example, in the current study words varied in length from two letters to nine letters. The durational difference between three-hundred millisecond words versus the difference between eighty millisecond words may prove to be significant. Examining the relative relationship between the durational differences of shorter words and of longer words might provide a researcher with further insight into the alterations a non-treated stutterer makes during fluent versus nonfluent productions of words varying in length. 


\section{REEERENCES}

Adams, M.A. (1987). Voice onsets and segment durations of normal speakers and beginning stutterers. Journal of Eluency Disorders, 12, 133-139.

Besozzi, T.E. \& Adams, M.R. (1969). The influence of prosody on stuttering adaptation. Journal of Speech and Hearing Research, 12, 818-824.

Bruce, M.C., \& Adams, M.R. (1978). Effects of two types of motor practice on stuttering adaptation. Journal of Speech and Hearing Research, 21, 421-428.

De Nil, I.F., \& Brutten, G.J. (1991). Voice onset times of stutterning and nonstuttering children: The influence of externally and linguistically imposed time pressure. Journal of Fluency Disorders, 16, 143-158.

Fairbanks, G. (1940). Voice and articulation drillbook. New York: Harper and Brothers.

Ham, R.E., (1990). Therapy of stuttering: Preschool through adolescence. New Jersey: Englewood Cliffs.

Howell, P., \& Wingfield, T. (1990). Perceptual and acoustic evidence for reduced fluency in the vicinity of stuttering episodes. Language and speech, 33, 31-46.

Johnson, w. (1967) . Stuttering. In Johnson, w. \& Moeller (Eds.), speech handicapped school children (3rd ed.) (pp. 229-329). New. York: Harper and Row.

Jaimeson, D.G., Ramji, K.V, Neary, T., \& Baxter, T. (1993) . computerized speech research environment. ontario: AVVAZ Interprises.

Klouda, G.V., \& Cooper, W.E. (1987). Syntactic clause boundaries, speech timing, and stuttering frequency in adult stutterers. Ianguage and Speech, 30, 263-276.

Metz, D.E., onufrak, J.A., \& Ogburn, R.S. (1979). An acoustical analysis of stutterer's speech prior to and at the terminiation of speech therapy. Journal of Eluency Disorders, 4, 249-254.

Metz, D.E., Samar, V.J., \& Sacco, P.R. (1983). Acoustic analysis of stutterers' fluent speech before and after therapy. Journal of Speech and Hearing Research, 26, 531-536. 
Metz, D.E., Schiavetti, N., \& Sacco, P.R. (1990). Acoustic and psychophysical dimensions of the perceived speech naturalness of nonstutterers and posttreatment stutterers. Journal of Speech and Hearing Disorders, 55, 516-525.

Onslow, M., Van Doorn, J., Newman, D., (1992). Variability of acoustic segment durations after prolonged-speech treatment for stuttering. Journal of speech and Hearing Research, 35, 529-536.

Perkins, W.H. (1990). What is stuttering? Journal of Speech and Hearing Disorders, 55, 370-382.

Pindzola, R.H. (1987). Durational characteristics of the fluent speech of stutterers and nonstutterers. Folia Phoniatrica, 32, 90-97.

Prins, D., \& Hubbard, C.P. (1990). Acoustical durations of speech segments during stuttering adaption. Journal of Speech and Hearing Research, 33, 494-504.

Prosek, R.A., \& Runyan, C.M. (1982). Temporal characteristics related to the discrimination of stutterers' and nonstutterers' speech samples. Journal of Speech and Hearing Research, 25, 29-33.

Runyan, C.M., \& Adams, M.R. (1978). Perceptual study of the speech of "successfully therapeutized" stutterers. Journal of Eluency Disorders, 3, 25-39.

Van Riper, c. (1971). The nature of stuttering. New Jersey: Englewood Cliffs.

Van Riper, C. (1973). The treatment of stuttering. New Jersey: Englewood Cliffs.

Viswanath, N.S. (1989). Global-and local-temporal effects of a stuttering event in the context of a clausal

utterance. Journal of Eluency Disorders, 14, 245-269.

Wendahl, R.W., \& Cole, J. (1961). Indentification of stuttering during relatively fluent speech. Journal of Speech and Hearing Research, 4, 281-286.

Williams, D.E. (1957). A point of view about 'stuttering.' Journal of Speech and Hearing Disorders, 22, 390-397.

Zimmermann, G. (1980a). Articulatory dynamics of fluent utterances of stutterers and nonstutterers. Journal of Speech and Hearing Research, 23, 95-108. 
Zimmermann, G. (1980b). Articulatory behaviors associated with stuttering: A cinefluorographic analysis. Journal of Speech and Hearing Research, 23, 109-121. 
CONSENT FORM

I

hereby

agree to take part in the study conducted by Jennifer

Peterson and Dr. John A. Tetnowski.

I understand that the study involves my coming to Portland state University for about two hours at which time I will read a list of sentences which will be tape recorded. In addition, I have been told that a test will be administered to determine the severity of my stuttering and a brief hearing screening will be conducted.

I have been informed that the purpose of this study is to gather data which will be used in furthering the knowledge of the treatment of stuttering. There will be no direct benefit to me. I further understand that my name and all identifying information will be kept completely confidential although a randomly assigned number will be used to differentiate subjects from one another.

I agree to allow results to be presented at professional meetings and/or conventions. I also agree to allow results to be printed in publications and/or professional journals. I understand that if results are used for any of these purposes, my name and identifying information will never be disclosed.

I have been told that a day-time parking permit will be issued to me (or my parent) to increase the convenience of coming to Portland state. 
I understand that I may withdraw from the study at any time and that this will not affect any services I might receive at Portland State University.

I have read and completely understand the above information. My signature indicates that I agree to participate in this study.

Date: Signature:

Date: Signature of Parent:

(Required if subject is under the age of 18)

If you have any questions or concerns regarding this research project, please contact Jennifer Peterson, Graduate student, Portland state University's speech and Hearing Program by leaving a message at the communications office 503/725-3533 or at home 503/653-3934. You may also contact the Chair of the Human subjects Review Committee, office for Research and Sponsored Projects, Portland State University, 503/725-3417. 
STUTTERING SEVERITY INSTRUMENT

(Riley and Riley, 1983)

Name :

Date of Birth:

Sex:

Age:

Date:

Examiner:

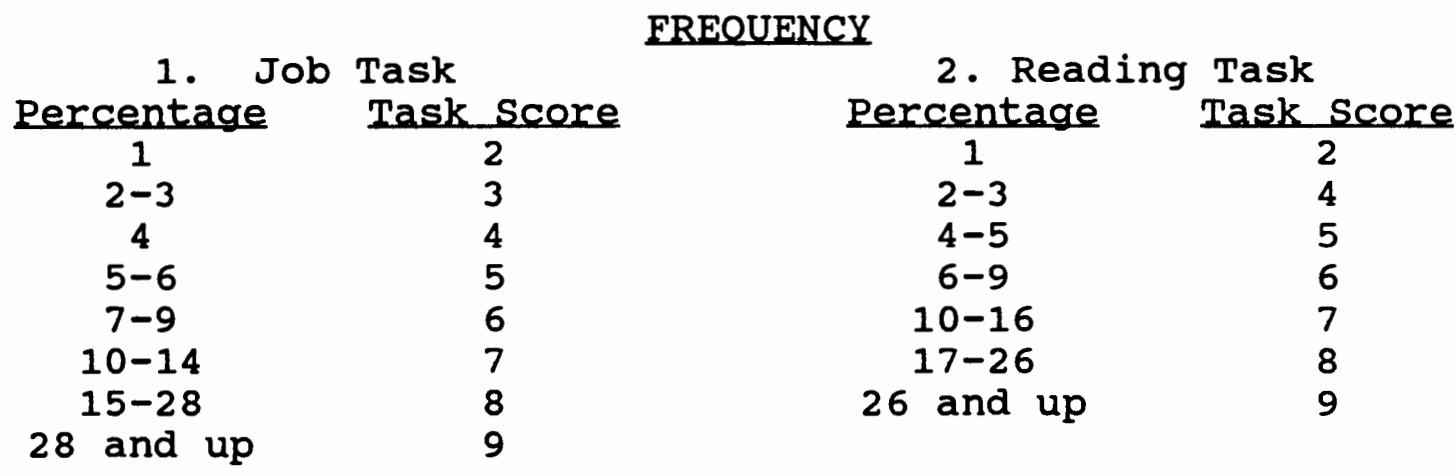

FREQUENCY TASK SCORE (1 and 2):

DURATION

Estimated Length of Three Longest Blocks Score

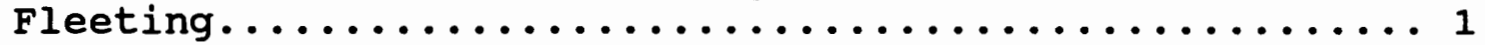

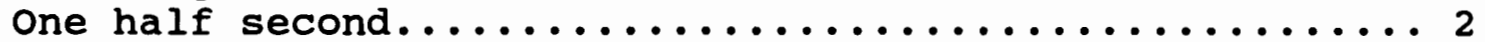

One full second.............................

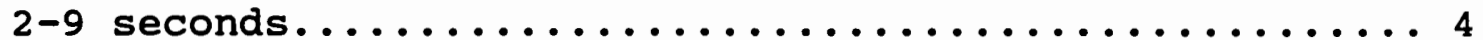

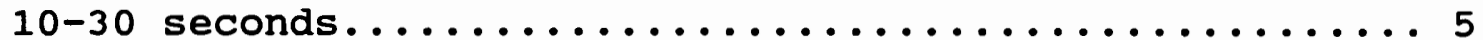

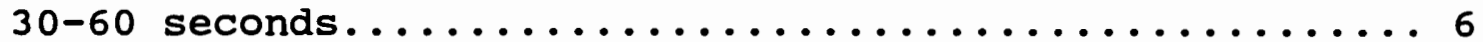

More than 60 seconds........................ 7

DURATION SCORE :

\section{PHYSICAI, CONCOMITANTS}

Evaluating Scale: $0=$ None, $1=$ Not noticeable unless looking for it, 2=Barely noticeable to casual observer, $3=$ Distracting, $4=$ =very distracting, 5=severe and painful looking.

Distracting sounds: Noisy breathing, whistling, 0122345 sniffing, blowing, clicking sounds.

Facial Grimaces: Jaw jerking, tongue $\quad 012345$ protruding, lip pressing, jaw muscles tense. 


\section{PHYSICAL CONCOMITANTS}

(continued)

Evaluating Scale: $0=$ None, 1 =Not noticeable unless looking for it, 2=Barely noticeable to casual observer, $3=$ Distracting, 4=Very distracting, 5=severe and painful looking.

Head Movements: Back, forward, turning away, $\quad 012345$ poor eye contact, constant looking around.

Movement of the Extremities: Arm and hand movement, hands about face, torso movement, leg movements, foot tapping or swinging.

TOTAL PHYSICAL CONCOMITANT SCORE:

TOTAL OVERALL SCORE:

CONVERSION TABLE

\begin{tabular}{c} 
Total overall score \\
\hline $0-16$ \\
$17-19$ \\
$20-21$ \\
$22-24$ \\
$25-27$ \\
$28-30$ \\
$31-33$ \\
$34-36$ \\
$37-45$
\end{tabular}

\begin{tabular}{c} 
Percentile \\
\hline $0-4$ \\
$5-11$ \\
$12-23$ \\
$24-40$ \\
$41-60$ \\
$61-77$ \\
$78-89$ \\
$90-96$ \\
$97-100$
\end{tabular}

Severity

Very Mild

Mild

Mild

Moderate

Moderate

Moderate

Severe

Severe

Very Severe 


\section{Sentences for Phonetic Inventory}

(Fairbanks, 1940)

1. Some people reason that seeing is believing.

2. They feel they are frequently deceived.

3. Bill saw a big pickerel swimming in the ripples.

4. He licked his lips in anticipation of a delicious fish dinner.

5. The agent remained away all day.

6. Late at night he made his way to the place where the sailors stayed.

7. Special regulations were necessary to help the selling of eggs.

8. Several senators expressed pleasure.

9. Sally banged the black sedan into a taxicab.

10. It was badly damaged by the crash.

11. I am unable to understand my Uncle Gus.

12. He mutters and mumbles about nothing.

13. John started across the yard toward the barn.

14. His father remarked calmly that he'd better not wander too far.

15. Is Shaw the author of "Walking on the Lawn"?

16. I thought it was Walter Hall.

17. Don't go home in the snow.

18. You'll be cold and soaked and half frozen.

19. Captain Hook pushed through the bushes to the brook. 20. From where he stood it looked like an ambush. 
21. As a rule, we go canoeing in the forenoon.

22. The pool is too cool in June.

23. Hugh refused to join the musicians' union.

24. His excuse was viewed with amusement.

25. Fowler wants to plow all the ground around his house.

26. Somehow I doubt if the council will allow it.

27. The tile workers were fighting for higher prices and more time off.

28. They tried to drive back the strike-breakers.

29. The boys toiled noisily in the boiling sun.

30. They enjoyed the work that Roy avoided.

31. First the girls turned on the furnace.

32. Then they worked on burning the dirty curtains.

33. I'll undertake it sooner or later.

34. Perhaps after another summer is over, in september or october.

35. Our barn is covered with brilliant red roses.

36. The broad crimson roof draws admiring crowds from far and near.

37. Lawyer clark held his little felt hat and his black gloves in his lap.

38. He silently placed the will on the table. 39. Mr. Miller had climbed many mountains. 40. But the chasm before him was the mightiest in his memory •

41. Laden down by their burdens, Dan and Ned ran from the 
barn into the open.

42. The tornado was not far distant.

43. The monks had no inkling that anything was wrong.

44. Suddenly the strong tones of the gong rang out.

45. Did you ever speculate on the uses of the familiar onion?

46. On the value of a yellow yam.

47. Wait until the weather is warm.

48. Then everyone will want to walk in the woods.

49. "What is that?" he whispered. Somewhere form the left came the whistle of a bobwhite.

50. Hurry back anyhow, Harry.

51. It will help if you only hear half the rehearsal.

52. Part way up the slope above the pool was a popular camping spot.

53. Many people stopped there for picnic suppers.

54. The British were not bothered about the robbery.

55. They believed they could bribe the Arab to betray his tribe.

56. After waiting for twenty minutes the train left the station.

57. The excited recruits sat and talked all night.

58. The doll's red dress was soiled and muddy.

59. But the ragged child hugged it adoringly.

60. Old Katy had a particular dislike for hawks and crows.

61. She called them "wicked creatures." 
62. The big dog began to dig under the log.

63. Gary forgot his hunger and grabbed his gun.

64. "For breakfast"" said father. "I find that coffee is the staff of life."

65. Grapefruit is a food for infants.

66. I believe I'Il save this heavy veil.

67. The vogue might be revived eventually.

68. We thought that the theory was pathetic.

69. But we had faith that something would lead to the truth.

70. My father finds it hard to breathe in this weather.

71. Even the heather withers.

72. The successful student does not assume that class exercise is sufficient.

73. He also practices by himself outside.

74. My cousin's play "The Zero Zone" is amusing.

75. But it won't be chosen for a prize because it doesn't deserve it.

76. The fishing ship was in shallows near the shore.

77. In one motion a wave crushed it on the shoal.

78. I make no allusion to sabotage.

79. But an explosion near that garage is unusual.

80. Mitchell was a righteous old bachelor.

81. He watched for a chance to chase the children out of his orchard.

82. All but the Judge Johnson pledged allegiance to the 
legislation.

83. He objected that it was unjust to the soldiers. 